Supporting Information

\title{
Facile synthesis of rapidly degrading PEG-based thiol-norbornene hydrogels
}

Fang-Yi Lin and Chien-Chi Lin*

Department of Biomedical Engineering, Purdue School of Engineering \& Technology, Indiana University-Purdue University Indianapolis, Indianapolis, IN 46202, USA

*Corresponding author: lincc@iupui.edu 


\section{Experimental section}

\section{Materials}

PEG-OH (8-arm, 20 kDa, JenKem), carbic anhydride (Sigma-Aldrich), 4-dimethylaminopyridine (DMAP, Alfa Aesar), dopamine hydrochloride (Sigma-Aldrich), tyramine hydrochloride (Chem-Impex), isopropylamine (TCI chemicals), N,N'-Diisopropylcarbodiimide (DIC, Chem-Impex), hydroxybenzotriazole (HOBt, $\geq 20$ wt\% water, Oakwood Chemical), N,N'-diisopropylethylamine (DIPEA, TCI chemicals), cysteine (Sigma-Aldrich), and lithium phenyl-2,4,6-trimethylbenzoylphosphinate (LAP, $\geq 95 \%$, Sigma-Aldrich), dithiothreitol (DTT, Fisher), 4-arms thiolated PEG (PEG4SH, 10 kDa, Laysan Bio), CRGDS (GenScript), CGPQG*IWGQC a matrix metalloproteinasesensitive peptide ('cleavage site, GenScript), 5,5'-dithiobis-(2-nitrobenzoic acid) (Ellman's reagent, Life Technologies), anhydrous tetrahydrofuran (THF, Fisher), anhydrous dimethylformamide (DMF, amine-free, Fisher), dichloromethane (DCM, Fisher), methanol (Sigma-Aldrich) and diethyl ether (Fisher) were used as received.

\section{PEGNB $_{\text {CA }}$ synthesis}

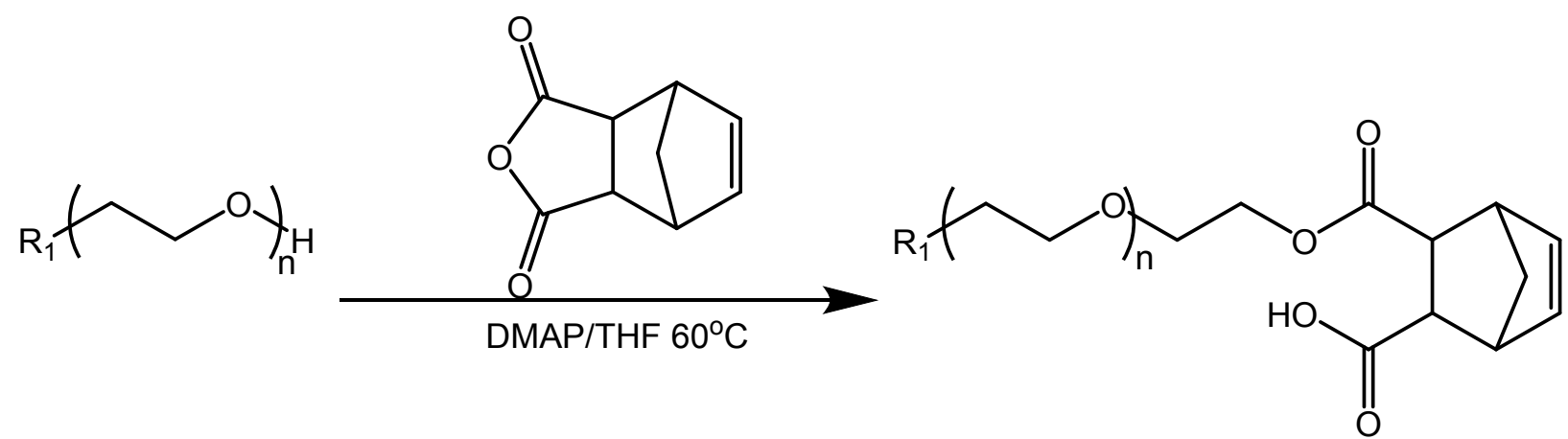

10 g PEG-OH (hydroxyl group $0.4 \mathrm{mmol}$ ), $3.28 \mathrm{~g}$ carbic anhydride (2 mmol, 5 equiv.), $0.49 \mathrm{~g}$ DMAP (0.4 mmol, 1 equiv.), and $83 \mathrm{~mL}$ anhydrous THF were charged in a round-bottom flask equipped with a stir bar. The reaction was conducted at $60^{\circ} \mathrm{C}$. After $12 \mathrm{~h}$, another portion of carbic anhydride and DMAP were added into the reaction. The reaction was continued for another $24 \mathrm{~h}$. The product was retrieved via precipitation through diethyl ether twice and subsequently dried in vacuum. The conventional PEGNB was synthesized according to Shih and Lin. ${ }^{1}$

\section{Norbornene substitution (NS) ratio determination}


<smiles>[R10]CCOCCOC(=O)C1C2C=CC(CC2C)C1C(=O)O</smiles>

The norbornene degree of substitution (NS) ratio was characterized by photo-activated thiol-ene reaction described as follows: the predetermined amounts of PEGNB, cysteine (Cys) and LAP were mixed in phosphate buffer solution. The final concentration of cysteine and LAP was $100 \mathrm{mM}$ and $2 \mathrm{mM}$, respectively. The solution was exposed under UV light $(\lambda=365 \mathrm{~nm}$ ) for $5 \mathrm{~min}$. The PEGNB-to-cysteine ratio ([PEGNB]/[Cys]) was controlled between 0.05 0.1 since the double bond from NB was not fully consumed at higher ratios (Figure S1). After diluted 100 times, the solution was reacted with Ellman's reagent to determine the residual cysteine amount.
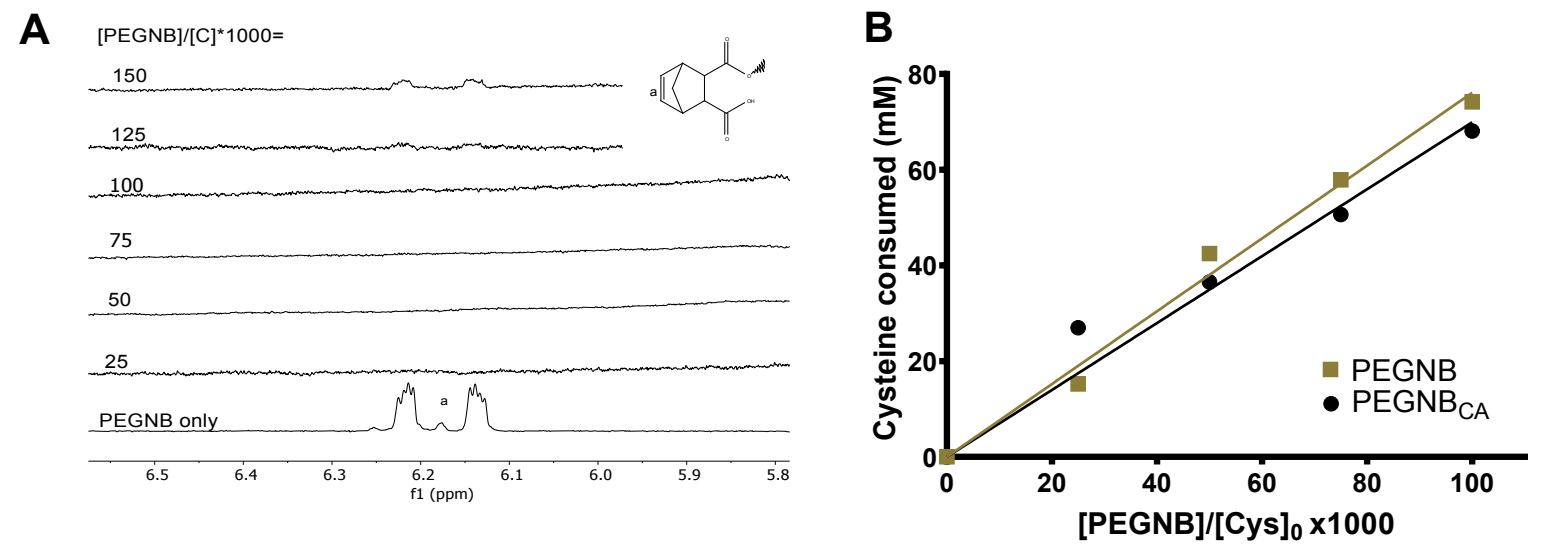

Figure S1. The suitable [PEGNB]/[Cys] ratio for Ellman's reagent in quantifying DS ratio by $\mathrm{A}^{1} \mathrm{H}$ NMR spectra and $\mathrm{B}$ quantification of residual cysteine using Ellman's assay. $[\mathrm{Cys}]_{0}=103 \mathrm{mM}, D S_{P E G N B C A}=87 \%$ 


\section{PEGNB-X synthesis}

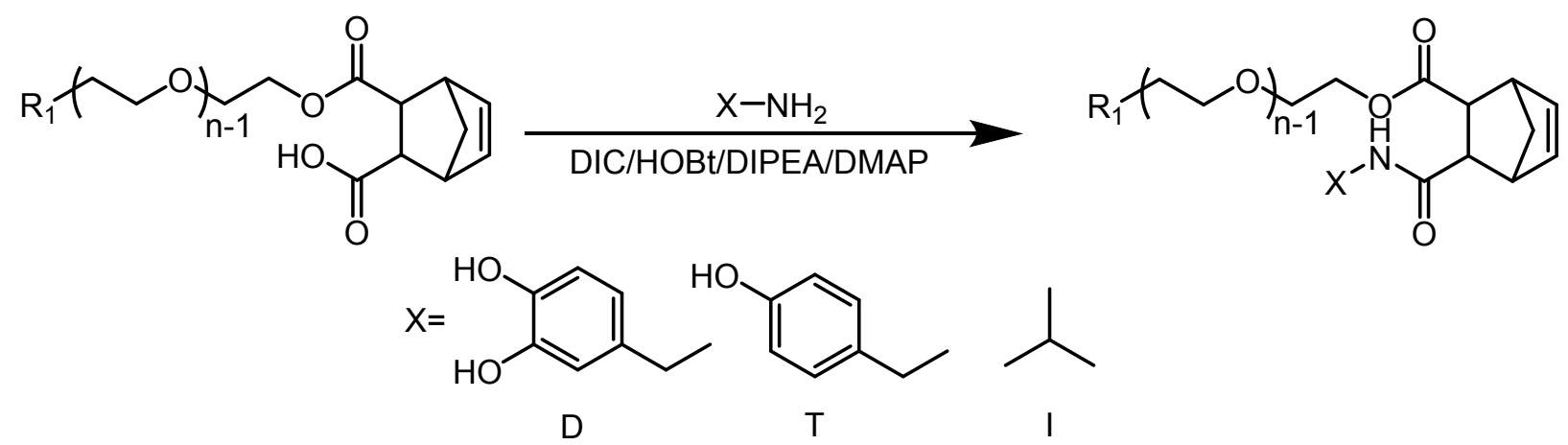

The method to conjugate amines with PEGNB ${ }_{C A}$ was adopted from Zhang et $\mathrm{al}^{2}$. To synthesize PEGNB $\mathrm{CA}_{\mathrm{A}}$

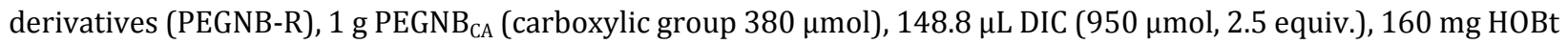
(950 $\mu \mathrm{mol}, 2.5$ equiv.) and $10 \mathrm{~mL}$ amine-free DMF were charged into a reaction vial equipped with a stir bar. The activation of the acid group was blanketed under nitrogen gas for $2 \mathrm{~h}$ in dark. Designated amount of amines (180 mg dopamine hydrochloride, $165 \mathrm{mg}$ tyramine hydrochloride, or $77.8 \mu \mathrm{L}$ isopropylamine , $950 \mu \mathrm{mol}, 2.5$ equiv.), 165.4 $\mu \mathrm{L}$ DIPEA (950 $\mu \mathrm{mol}, 2.5$ equiv.), and $23 \mathrm{mg}$ DMAP (190 $\mu \mathrm{mol}, 0.5$ equiv.) were dissolved in $1 \mathrm{~mL}$ amine-free DMF and then added into the reaction. The reaction was continued overnight. The product was dialyzed in methanol for one day and dried out in vacuum. The product was characterized by ${ }^{1} \mathrm{H}$ NMR spectra (Bruker $500 \mathrm{MHz}$ ) in Figure S2.

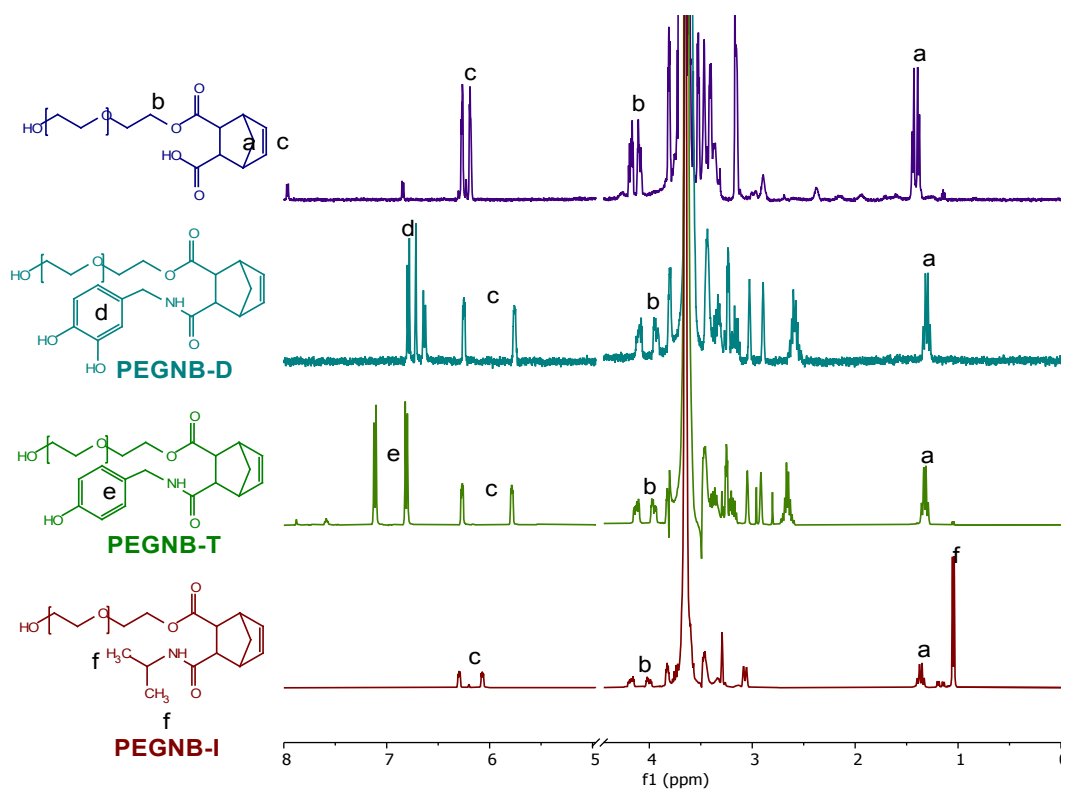

Figure S2. ${ }^{1} \mathrm{H}$ NMR spectra of PEGNB ${ }_{C A}$, PEGNB-D, PEGNB-T, and PEGNB-I. The conversion of PEGNB-D, PEGNB-T, and PEGNB-I with respect to the norbornene group is $100 \%, 97 \%$, and $83 \%$ respectively. 


\section{Hydrogel fabrication}

For rheological testing, predetermined amount of PEGNB, PEGNB $\mathrm{CA}_{\text {A }}$ or PEGNB-Xs and DTT precursor solutions were mixed in phosphate buffer solution (PBS). $45 \mu \mathrm{L}$ precursor solution was deposited between glass slides with $1 \mathrm{~mm}$ spacer and crosslinked by LAP under UV light $\left(\lambda=365 \mathrm{~nm}, 5 \mathrm{~mW} / \mathrm{cm}^{2}\right)$ to afford hydrogel. The formulation details use in each figure are summarized in 
Table S1. The 0 h rheological results of PEGNB-X hydrogels shown in Figure 4, 5, and S5 were acquired right after cured. Hydrogels were incubated in PBS at $37^{\circ} \mathrm{C}$ between all testings except in Figure S4, which was kept at room temperature. Expect the in-situ acquisition in Figure 1B, the dynamic shear rheology measurement was conducted by Malvern Bohlin CVO 100 rheometer with $8 \mathrm{~mm}$ parallel plates. The shear modulus was determined by strain sweep between strain of 0.1 and $5 \%$ at $1 \mathrm{~Hz}$ with a gap size of $700 \mu \mathrm{m}$. For the in-situ gelation acquisition in Figure 1B, $100 \mu \mathrm{L}$ precursor solution was deposited between $25 \mathrm{~mm}$ parallel plates with a gap size of $90 \mu \mathrm{m}$. Modulus data were acquired at $1 \mathrm{~Hz}$ with UV light $\left(\lambda=365 \mathrm{~nm}, 5 \mathrm{~mW} / \mathrm{cm}^{2}\right)$ shed between $\mathrm{t}=20-140 \mathrm{~s}$ for a total $5 \mathrm{~min}$ acquisition period. All results were averaged from 3 replicates.

For gravimetric swelling measurements, hydrogels were fabricated similarly to those for rheological testing except that the precursor solutions were prepared in double-distilled water (ddH2O). See formulation details in 
Table S1. The fabricated hydrogels were vacuum dried to obtain dried gel weight $\left(\mathrm{W}_{\mathrm{dry}}\right)$ prior to incubated in PBS at $37^{\circ} \mathrm{C}$ or room temperature. The swollen gel weight $\left(\mathrm{W}_{\text {swollen }}\right)$ was recorded at predetermined time point. The mass swelling ratio $(Q)$ is then defined as $Q=W_{\text {swollen }} / W_{d r y}$. All results were averaged from 3 replicates.

\section{Pseudo-first order hydrolytic degradation model fitting}

The remaining ester fraction in PEGNB $\mathrm{CA}_{\mathrm{A}}$ and PEGNB-X hydrogels can be described by $\mathrm{G}^{\prime}(\mathrm{t}) / \mathrm{G}_{0}^{\prime}$ in addition to the swelling ratio. For a pure ester hydrolysis system, the degradation kinetics can be expressed by a pseudo-first

order equation. ${ }^{1,3,4}$ Thus, we can obtain the apparent hydrolysis rate constant $\left(\mathrm{k}_{\mathrm{hyd}}\right)$ from $G^{\prime}(t) / G^{\prime}{ }_{0} \propto e^{-k_{h y d} t}$ or $q / q_{0} \propto e^{k} h y d^{t}$ 
Table S1. Summary of hydrogel formulations

\begin{tabular}{|c|c|c|c|c|c|c|c|}
\hline Figure & $\begin{array}{c}\text { Norbornene } \\
\text { source }\end{array}$ & $\begin{array}{c}\text { PEGNB, } \\
\text { PEGNB }_{\mathrm{CA}} \text {, or } \\
\text { PEGNB-R wt\% }\end{array}$ & Crosslinker & $\begin{array}{c}\text { Thiol/ene } \\
\text { ratio }\end{array}$ & $\begin{array}{l}\text { [CRGDS } \\
](\mathrm{mM})\end{array}$ & $\begin{array}{l}\text { [LAP] } \\
(\mathrm{mM})\end{array}$ & $\begin{array}{c}\text { UV } \\
\text { exposure } \\
\text { time (min) }\end{array}$ \\
\hline $1 \mathrm{~B}$ & $\mathrm{PEGNB}_{\mathrm{CA}}$ & 2.5 & DTT & 1 & 0 & 1 & 2 \\
\hline $1 \mathrm{C}$ & $\mathrm{PEGNB}_{\mathrm{CA}}$ & varies & DTT & 1 & 0 & 1 & 2 \\
\hline $1 \mathrm{C}$ & PEGNB & varies & DTT & 1 & 0 & 1 & 2 \\
\hline 2B and S3 & PEGNB $_{\mathrm{CA}}$ & 4 & DTT & 1 & 0 & 1 & 2 \\
\hline 2B and S3 & PEGNB & 2.5 & DTT & 1 & 0 & 1 & 2 \\
\hline 3 (hiPSC) & $\mathrm{PEGNB}_{\mathrm{CA}}$ & 4 & CGPQG*IWGQC & 0.9 & 1 & 1 & 2 \\
\hline $\begin{array}{c}3 \text { (DPSC } \\
\text { and } \\
\text { PANC-1) }\end{array}$ & $\mathrm{PEGNB}_{\mathrm{CA}}$ & 4 & CGPQG*IWGQC & 0.936 & 1 & 1 & 2 \\
\hline 4 & PEGNB-X & 4 & DTT & 1 & 0 & 1 & 2 \\
\hline $5 \mathrm{~A}$ and $\mathrm{B}$ & PEGNB-D & 4 & DTT or PEG4SH & 1 & 0 & 1 & 2 \\
\hline $5 \mathrm{C}$ and $\mathrm{D}$ & $\begin{aligned} & \text { PEGNB }_{\mathrm{CA}} \\
+ & +\mathrm{PEGNB}-\mathrm{D}\end{aligned}$ & $\begin{array}{c}4 \\
\text { (in total) }\end{array}$ & DTT & 1 & 0 & 1 & 2 \\
\hline S4 & PEGNB-X & 4 & DTT & 1 & 0 & 1 & 2 \\
\hline S5 and S6 & $\begin{aligned} & \text { PEGNB }_{\mathrm{CA}} \\
+ & \text { PEGNB-D }\end{aligned}$ & $\begin{array}{c}10 \\
\text { (in total) }\end{array}$ & DTT & 1 & 0 & 5 & 5 \\
\hline S7 and S8 & $\begin{aligned} & \text { PEGNB }_{\mathrm{CA}} \\
+ & \text { PEGNB-D }\end{aligned}$ & 4 & CGPQG*IWGQC & 0.936 & 1 & 1 & 2 \\
\hline
\end{tabular}




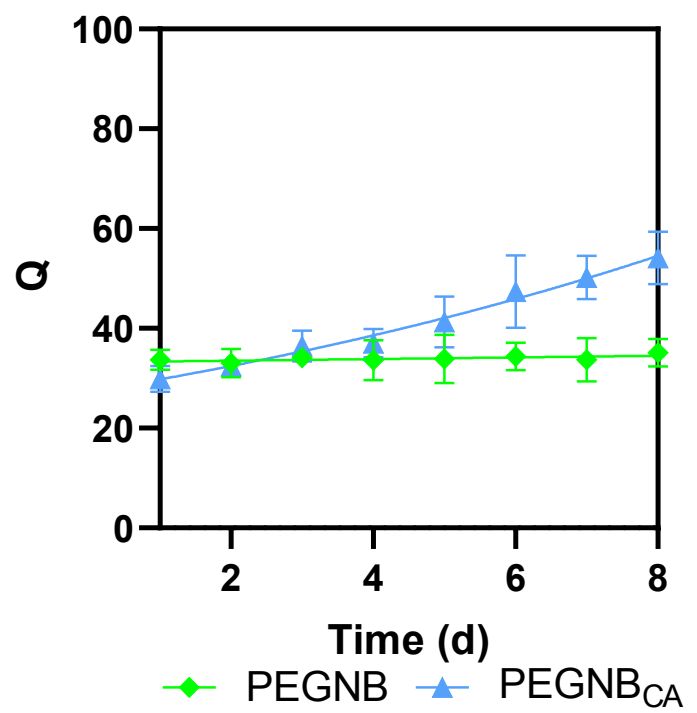

Figure S3. Degradation of PEGNB/PEGNB ${ }_{\mathrm{CA}}$ hydrogels at $37^{\circ} \mathrm{C}$ by swelling ratio.

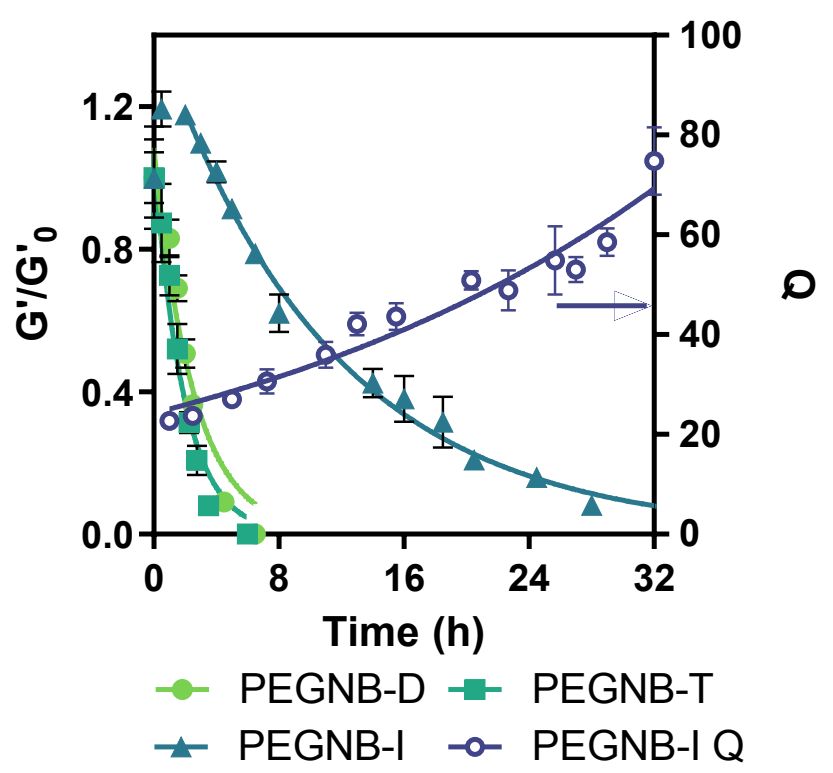

Figure S4. Degradation of PEGNB-X hydrogels at room temperature. 
Table S2. Parameters of pseudo-first order ester hydrolysis kinetics of PEGNB-X hydrogels at room temperature (Figure S4)

\begin{tabular}{|c|c|c|c|}
\hline PEGNB-X & PEGNB-D & PEGNB-T & 0.09 \\
\hline $\mathrm{k}_{\mathrm{hyd}}\left(\mathrm{h}^{-1}\right)$ & 0.39 & 0.52 & 0.98 \\
\hline $\mathrm{R}^{2}$ & 0.93 & 0.95 & \\
\hline
\end{tabular}

Table S3. Parameters of pseudo-first order ester hydrolysis kinetics of PEGNB-D crosslinked with DTT and PEG4SH hydrogels at $37^{\circ} \mathrm{C}$ (Figure $5 \mathrm{~A}$ and $\mathrm{B}$ )

\begin{tabular}{|l|l|l|}
\hline Crosslinker & DTT & PEG4SH \\
\hline $\mathrm{k}_{\mathrm{hyd}}\left(\mathrm{h}^{-1}\right)$ & 1.46 & 0.49 \\
\hline $\mathrm{R}^{2}$ & 0.97 & 0.91 \\
\hline
\end{tabular}

Table S4. Parameters of pseudo-first order ester hydrolysis kinetics of 4 wt $\%$ PEGNB $_{\mathrm{CA}} /$ PEGNB-D hydrogels (Figure 5C, and D) at $37^{\circ} \mathrm{C}$

\begin{tabular}{|c|c|c|}
\hline PEGNB-D \% & $\mathrm{k}_{\text {hyd }}\left(\mathrm{d}^{-1}\right)$ & $\mathrm{R}^{2}$ \\
\hline 0 & 0.19 & 0.97 \\
\hline 10 & 0.31 & 0.92 \\
\hline 15 & 0.82 & 0.96 \\
\hline 20 & 1.19 & 0.98 \\
\hline
\end{tabular}



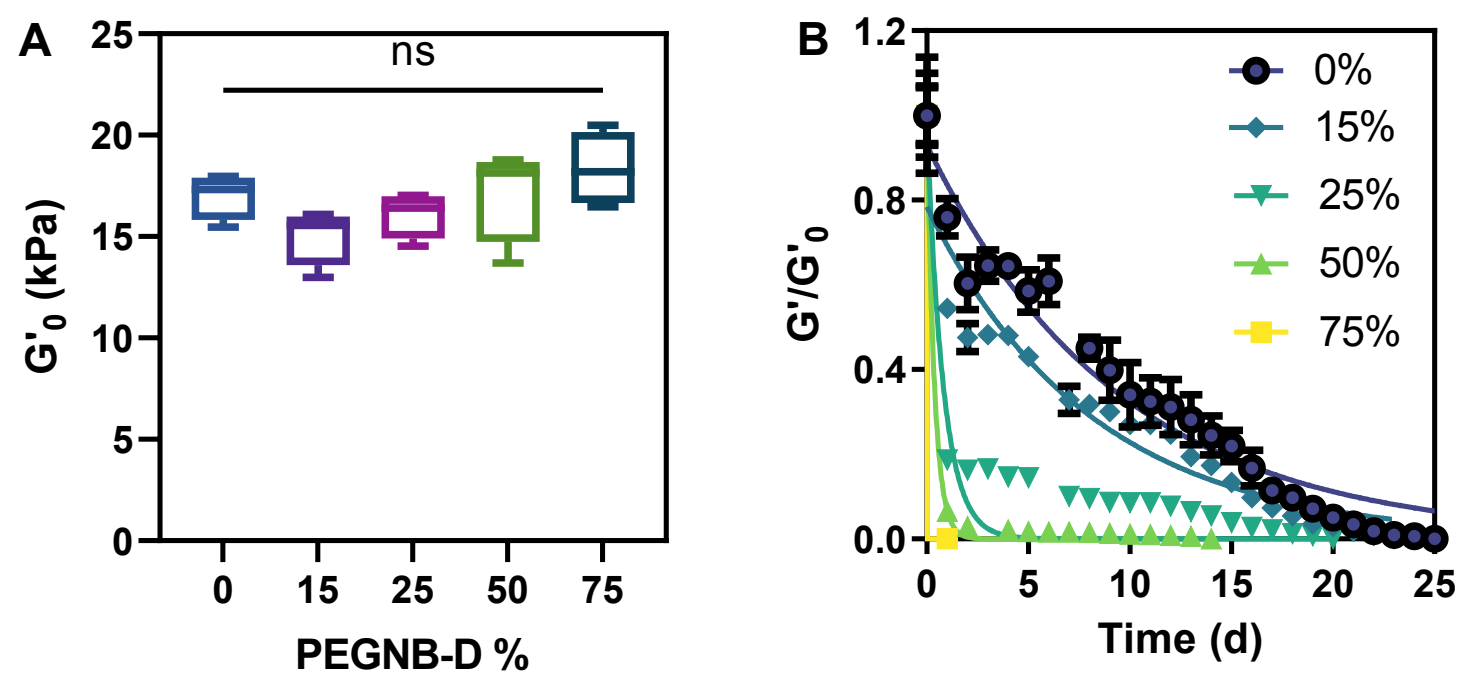

Figure S5. (A) Initial shear moduli and (B) degradation of $10 \mathrm{wt} \%$ PEGNB $_{\mathrm{CA}} /$ PEGNB-D-DTT hydrogels with different PEGNB-D content.

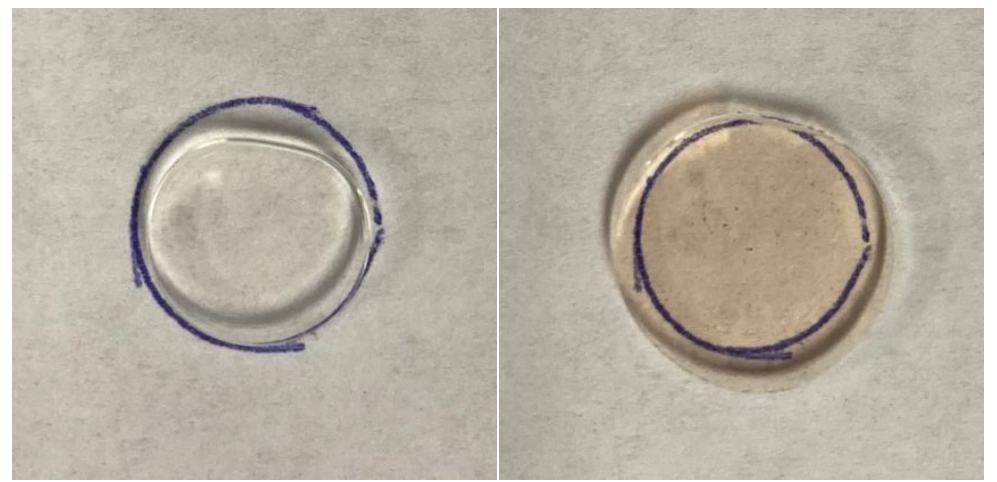

Figure S6. $10 \mathrm{wt} \%$ PEGNB-D 25\% hydrogel on Day 0 (left) and Day 7 (right). The circle diameter is $9 \mathrm{~mm}$. 


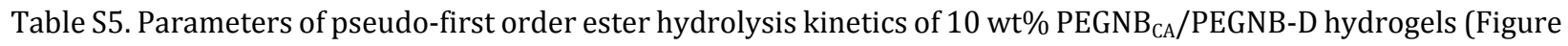
S5) at $37^{\circ} \mathrm{C}$

\begin{tabular}{|c|c|c|}
\hline PEGNB-D \% & $\mathrm{k}_{\text {hyd }}\left(\mathrm{d}^{-1}\right)$ & $\mathrm{R}^{2}$ \\
\hline 0 & 0.11 & 0.95 \\
\hline 15 & 0.12 & 0.91 \\
\hline 25 & 1.23 & 0.89 \\
\hline 50 & 2.68 & 0.99 \\
\hline
\end{tabular}

\section{Cell culture and the subsequent encapsulation in PEGNB CA $_{\text {hydrogels }}$}

Cellartis hiPSC line 12 (hiPSC) were maintained in Essential 8 (E8) medium (Gibco) on tissue culture plates coated with vitronectin (Gibco) per manufacturer's protocol. Media was refreshed daily, and passaging was conducted using TrypLE Select reagent (Gibco) treatment for 5 minutes every 3-4 days. During the first 24 hours after passaging, media was supplemented with ROCK inhibitor Y-27632 (10 $\mu \mathrm{M})$ to prevent cell death. For encapsulated iPSCs, Y$27632(10 \mu \mathrm{M})$ was added to E8 medium for the duration of the experiment. Dental pulp stem cells (DPSC) were cultured in low glucose Dulbecco's modified Eagle's medium (DEME, Gibco) containing $10 \%$ fetal bovine serum (FBS, Gibco) and $1 \%$ penicillin-streptomycin (Gibco) incubated at $37{ }^{\circ} \mathrm{C}$ with $5 \% \mathrm{CO}_{2}$. DPSC were trypsinated by $0.5 \%$ trypsin and suspended in hydrogel precursor solution at 2 Mcell/mL. PANC-1 cells, a human pancreatic cancer cell line, were cultured in high glucose Dulbecco's modified Eagle's medium (DEME, Gibco) containing 10\% fetal bovine serum (FBS, Gibco) and 1\% penicillin-streptomycin (Gibco) incubated at $37{ }^{\circ} \mathrm{C}$ with $5 \% \mathrm{CO}_{2}$. PANC-1 cells were trypsinated by $1 \%$ trypsin and suspended in hydrogel precursor solution at $2 \mathrm{Mcell} / \mathrm{mL}$.

To encapsulate cells in hydrogels, $25 \mu \mathrm{L}$ of cell precursor solution (see formulation details in 
Table S1) was loaded in a cut-opened $1 \mathrm{~mL}$ syringe and exposed to UV light $\left(\lambda=365 \mathrm{~nm}, 5 \mathrm{~mW} / \mathrm{cm}^{2}\right)$ for 2 min. The cell-laden hydrogels were then cultured in regular cell culture media. The cell viability was evaluated by staining hydrogels with calcein AM/ethidium homodimer 1 live/dead staining kit prior to confocal imaging (Olympus Fluoview FV100 laser scanning microscope). Images were z-staged from $10 \mu \mathrm{m}$ slices over $100 \mu \mathrm{m}$ in total.
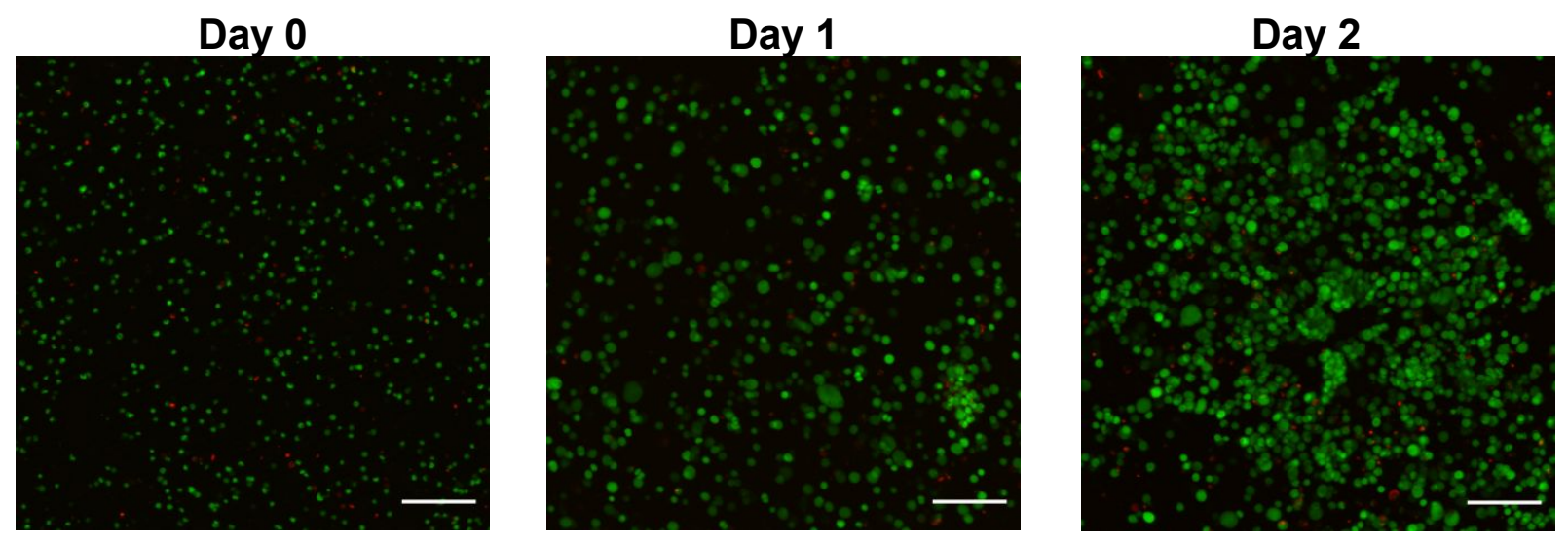

Live/Dead (Scale bars: $200 \mu \mathrm{m})$

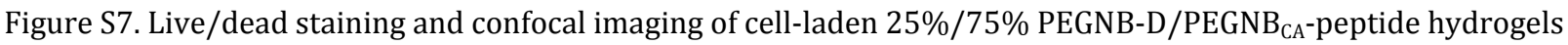
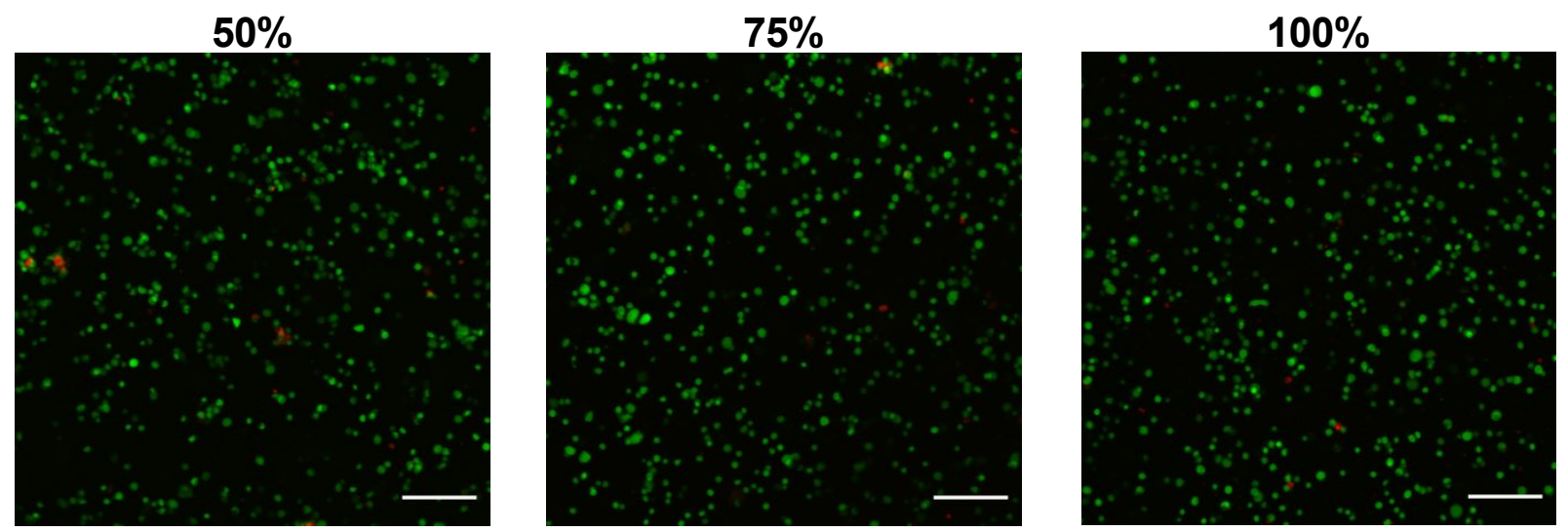

Live/Dead (Scale bars: $200 \mu \mathrm{m})$

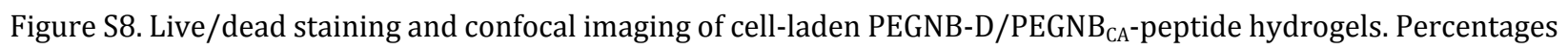
are the PEGNB-D ratio in the composites.

\section{References}

(1) Shih, H.; Lin, C. C. Cross-Linking and Degradation of Step-Growth Hydrogels Formed by Thiol-Ene Photoclick Chemistry. Biomacromolecules 2012, 13 (7), 2003-2012. 
(2) Zhang, K.; Wei, Z.; Xu, X.; Feng, Q.; Xu, J.; Bian, L. Efficient Catechol Functionalization of Biopolymeric Hydrogels for Effective Multiscale Bioadhesion. Mater. Sci. Eng. C 2019, 103, 109835.

(3) Metters, A. T.; Bowman, C. N.; Anseth, K. S. A Statistical Kinetic Model for the Bulk Degradation of PLAb-PEG-b-PLA Hydrogel Networks. J. Phys. Chem. B 2000, 104 (30), 7043-7049.

(4) Metters, A. T.; Anseth, K. S.; Bowman, C. N. A Statistical Kinetic Model for the Bulk Degradation of PLAb-PEG-b-PLA Hydrogel Networks: Incorporating Network Non-Idealities. J. Phys. Chem. B 2001, 105 (34), 8069-8076. 